\title{
Unnecessary antimicrobial prescribing for upper respiratory tract infections in children in Pietermaritzburg, South Africa
}

\author{
Lehlohonolo John Mathibe ${ }^{1}$, Nonhle Perseverance Zwane ${ }^{2}$
}

\begin{abstract}
1. Division of Pharmacology (Therapeutics), Nelson R. Mandela School of Medicine, University of KwaZulu-Natal, South Africa.

2. Aspen Pharmacare, Port Elizabeth, South Africa.
\end{abstract}

\begin{abstract}
Background: Acute upper respiratory tract infections (URTIs) are contagious diseases of the upper airways, but they are self-limiting in nature. Therefore, antimicrobial-use for the majority of the URTIs is considered inappropriate. Unfortunately, globally, antimicrobials are still being prescribed for the treatment of URTIs, especially in children. However, there is insufficient evidence on the causes of this phenomenon in South Africa.

Objective: To investigate whether the parents/guardians accompanying children with URTIs expected/influenced physicians and/or nurses to prescribe antibiotics.

Methods: This was a prospective descriptive and explorative questionnaire-based study. Participants were guardians who accompanied children aged five years and below, diagnosed with acute URTIs.

Findings: Three hundred and six parents/guardians participated in this study. Seventy six percent ( $\mathrm{n}=233$ ) of participants received antibiotics for URTIs for their children, and $67 \%(\mathrm{n}=156)$ of these did not make requests for antimicrobial therapy. On overall, there was a statistically significant ( $\mathrm{p}<0.0001$ ) chance (with OR of 5.9; 95\% CI, $2.4-14.2$ ) for receiving antibiotics for URTIs without a request.

Conclusion: Physicians and other healthcare providers need education on rational prescribing of antimicrobials, and to implement evidence-based standard treatment guidelines, to reduce inappropriate use of antibiotics in children with self-limiting URTIs.
\end{abstract}

Keywords: Antibiotics, antimicrobials, prescribing, upper respiratory tract infections, children.

DOI: https://dx.doi.org/10.4314/ahs.v20i3.15

Cite as: Mathibe LJ, Zwane NP. Unnecessary antimicrobial prescribing for upper respiratory tract infections in children in Pietermaritzburg, South Africa. Afri Health Sci. 2020;20(3):1133-1142. https:/ / dx.doi.org/10.4314/ahs.v20i3.15

\section{Background}

Antibiotics have changed the world and saved millions of lives. ${ }^{1,2}$ Infectious diseases which used to kill many people in the past, can now be cured. More importantly, these medicines are relatively safe compared to many other drugs which cause serious side effects. ${ }^{3}$ However, irrational/inappropriate or even unnecessary prescribing weaken the most powerful "weapons" available to all healthcare professionals in the fight against life-threatening infections. The World Health Organisation (WHO) has defined rational prescribing of antibiotics, in particular, as 'the cost-effective use of antibi-

\section{Corresponding author:}

Lehlohonolo John Mathibe,

Division of Pharmacology (Therapeutics),

Nelson R. Mandela School of Medicine,

University of KwaZulu-Natal, South Africa.

Email: mathibel@ukzn.ac.za otics which maximises clinical therapeutic effect while minimising both drug-related toxicity and the development of antimicrobial resistance. ${ }^{4}$ In general, the Centre for Disease Control (CDC) Interagency Task Force on Antimicrobial Resistance has defined rational or appropriate prescribing as the 'use that maximises therapeutic impact while minimising toxicity and the development of resistance'. ${ }^{5}$ In clinical practice, this means a healthcare provider prescribes antimicrobial therapy only when it is beneficial to the patient -- using the correct medicine and dosage. For the out-patients, specifically, providing simple and proper information, instructions and warnings about antibiotic therapy is the most important part of rational prescribing process. ${ }^{6}$

Irrational prescribing of antibiotics is a major factor that contributes to an ever-increasing development of antimicrobial resistance (AMR) globally. ${ }^{7}$ Increased AMR in the world can cause serious infections, complications and death. ${ }^{8}$ If no action is taken, AMR will 
approximately cause 10 million deaths per year in the world by $2050 .{ }^{9}$ Non-adherence to treatment guidelines leads to irrational use of medicines. ${ }^{2}$ Therefore, effective implementation of evidence-based standard treatment guidelines and practices for antimicrobial use, and quantifying of the extent to which irrational prescribing of antimicrobial is occurring across the world, lower prevalence of AMR. ${ }^{10}$

In the developing countries it is more crucial to measure and reduce irrational prescribing and misuse of antimicrobial because of high incidences of deaths due to respiratory infections, especially in children, and scarcity of resources. ${ }^{11,12,13}$ In sub-Saharan Africa, in particular, prevention of irrational antibiotic prescribing is important mainly because of high rates of infectious diseases. ${ }^{14,15}$ Antibiotic therapy is crucial and beneficial for the management of severe and life-threatening lower respiratory infections, especially in infants and children. ${ }^{16,17}$ However, antibiotics have no benefit for the treatment of upper respiratory tract infections (URTIs) such as common cold and viral rhinitis. ${ }^{18,19}$ Unfortunately, up to $70 \%$ of patients who seek medical care for $90 \%$ of URTIs receive antibiotic therapy. ${ }^{20,21}$ Therefore, the main aim of this study was to investigate whether the parents/guardians accompanying children with childhood URTIs expected or influenced physicians/ nurses to prescribe antibiotics. The parents/guardians knowledge on storage/reconstitution of antibiotics as well as antimicrobial resistance was also investigated.

\section{Methods}

\section{Study Setting}

This was a prospective descriptive and explorative questionnaire-based study. Data collection took place at a Community Health Centre (CHC), situated in the urban area in the uMsunduzi Municipality, in Pietermaritzburg, South Africa. The CHCs, district level public health services, are regarded as Step 2 health facilities in South Africa. In addition to the services that are usually provided at primary healthcare clinics (i.e., the Step 1 health facilities in South Africa), the CHCs normally provide a 24-hour maternity as well as trauma and emergency services. There are no usual "in-patients" stay or admissions at the CHCs, as it the case with hospitals. However, CHCs in South Africa have limited beds where patients could be observed for a maximum of 48 hours. ${ }^{22}$ Some CHC patients are seen by the nurses with prescribing licences. However, in these limited instances, doctors co-sign all the prescriptions issued by the nurses for the $\mathrm{CHC}$ pharmacist(s) to dispense. Parents (or guardians) who accompanied children aged five years and below, diagnosed (as per prescription or patients' medical chart) with childhood URTIs (ICD10-CM Code J06.9), were included in this study. Recruitment took place after all patients were seen by the doctors/nurses, and the prescribers were not aware that the parents/guardians of their patients were going to be recruited to participate in this study.

All questionnaires, with closed-ended questions, were administered by a registered pharmacist fluent in English and isiZulu, which are the main languages spoken in the area where data collection took place. Some items in the questionnaire required either Yes/No answers (e.g., "have you ever heard about antibiotic resistance"); other items had four options to choose from (e.g., "did you request for an antibiotic(s) to be prescribed or issued for your child" - Yes and it was given/Yes, but it not given/No I did not request it, but it was issued/No, I did not request it, and was not given).

\section{Ethics clearance, data collection and analysis}

The KwaZulu-Natal Provincial Department of Health Research and Ethics Committee, as well as the University of KwaZulu-Natal (UKZN) Biomedical Research Ethics Committee granted full ethics approval (Ref.: BE 089/18) to conduct this study. Data were collected during week days (Monday, Wednesday and Friday) from both the paediatric and outpatient departments. Recruitment took place on these days, because usually the paediatrician would be present and there were substantial numbers of children attended to at the two departments of the CHC. Questionnaire development and analyses were informed by Nyquist and colleagues. ${ }^{18}$ To assess association between various variables, participants' ages were categorised into three age groups. That is, $\leq 19$ years olds (children \& teenagers), $20-35$ years olds (youth \& young adults) and $\geq 36$ years olds (adults $\&$ the elderly). Statistical significance for categorical variables was tested using the Chi square test at $5 \%$ level of significance. Differences with p-values less than 0.05 were considered significant. Estimates of associations were expressed using odds ratios (OR) with their 95\% confidence intervals $(95 \% \mathrm{CI})$.

\section{Results \\ Demographic information of study participants}

Three hundred and eighty eight eligible (388) participants were contacted. However, and for the various logistical reasons, 82 eligible parents/guardians refused to participate in this study. Therefore, three hundred 
and six $(\mathrm{N}=306)$ with the average age of 29.1 years (sd, \pm 9.5 years) respondents gave consent and participated in this study. Two hundred and fifty two $(82 \%)$ were females and only $54(18 \%)$ were males, with average age of 29 years (ranging from 16 to 62 years old). As shown in Table $1,71 \%(\mathrm{n}=217)$ of participants resided in the townships, and with regards to age-groupings, the majority $(61 \%, n=186)$ of participants were youth and young adults.

Table 1: Demographic characteristics of the participants $(\mathrm{N}=306)$

\begin{tabular}{|l|l|c|c|}
\hline \multicolumn{1}{|c|}{ Variables } & \multicolumn{1}{|c|}{ Categories } & N & Percentage \\
\hline Race & Blacks & 180 & $59 \%$ \\
& Coloureds & 79 & $26 \%$ \\
& Indians & 31 & $10 \%$ \\
& Whites & 16 & $5 \%$ \\
\hline \multirow{2}{*}{ Gender } & Females & 252 & $82 \%$ \\
& Males & 54 & $18 \%$ \\
\hline Age & $\leq 19$ years olds & 55 & $18 \%$ \\
& $20-35$ years olds & 186 & $61 \%$ \\
& $\geq 36$ years olds & 65 & $21 \%$ \\
\hline \multirow{2}{*}{ Location/Residence } & Rural & 71 & $23 \%$ \\
& Township & 217 & $71 \%$ \\
& Suburban & 18 & $6 \%$ \\
\hline Parents Education & Primary & 13 & $4 \%$ \\
& Secondary & 137 & $45 \%$ \\
& Matric & 108 & $35 \%$ \\
& Higher/ College & 48 & $16 \%$ \\
\hline
\end{tabular}

\section{Requesting/receiving antibiotics}

Seventy six percent ( $\mathrm{n}=233$ ) of participants received antibiotics for URTIs for their children, and 67\% ( $\mathrm{n}=156)$, of these, did not make requests for antimicrobial therapy. On overall, there was a statistically significant ( $\mathrm{p}<$ 0.0001 ) chance (with OR of 5.9; 95\% CI, 2.4 - 14.2) for receiving antibiotics for URTIs without a request. In particular, as shown in Figure 1, participants aged $\geq 36$ years showed a statistically significant $(\mathrm{p}=0.04) \mathrm{OR}$ of 10.7 (95\% CI, 5.8 - 19.3) for the chance of receiving antibiotics for URTIs without a request. In total, that is irrespective of whether they received antibiotic therapy, $73 \%(\mathrm{n}=223)$ of patients who participated in this study did not ask the doctors/nurses to prescribe antibiotics.
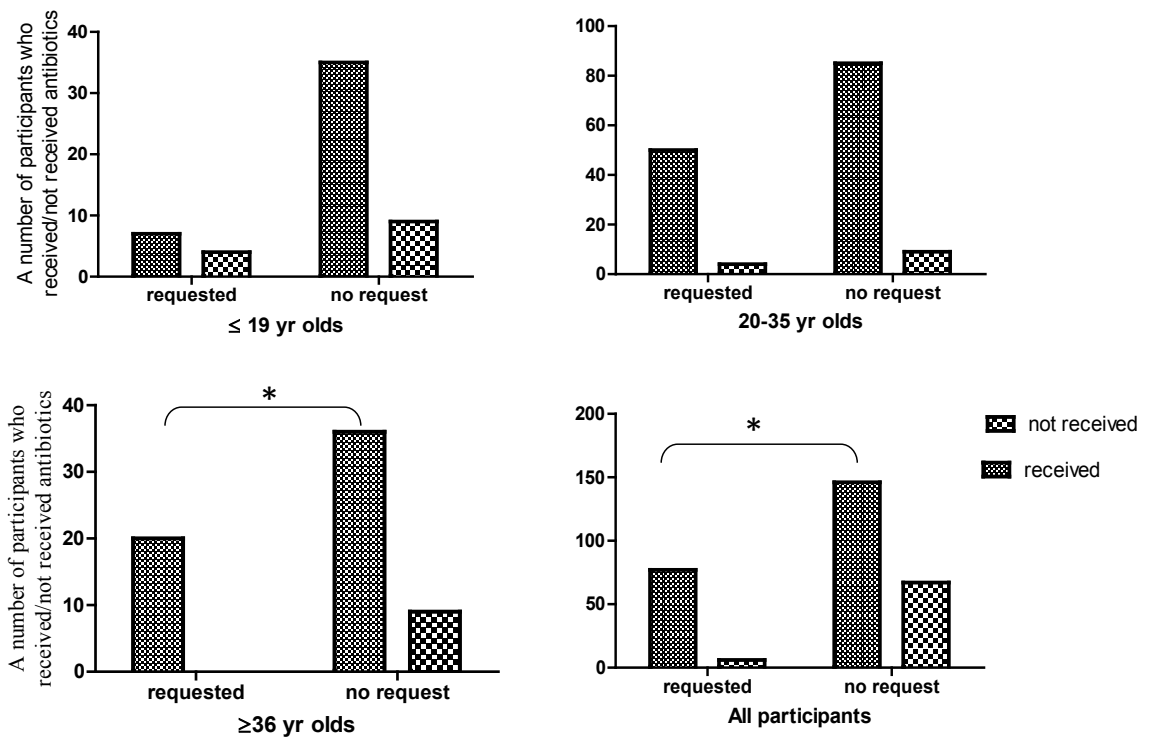

Figure 1: Prescribing of antibiotics as result of requests or no requests from parents/guardians. ${ }^{*} \mathrm{p}<0.01$ 
The Coloureds were marginally less likely (with odds $=$

2.7) to receive antibiotics, irrespective of requesting for them, as compared to Blacks, Indians and Whites with the odds of 3.4, 3.9 and 3.0, respectively (please refer to Figure 2).

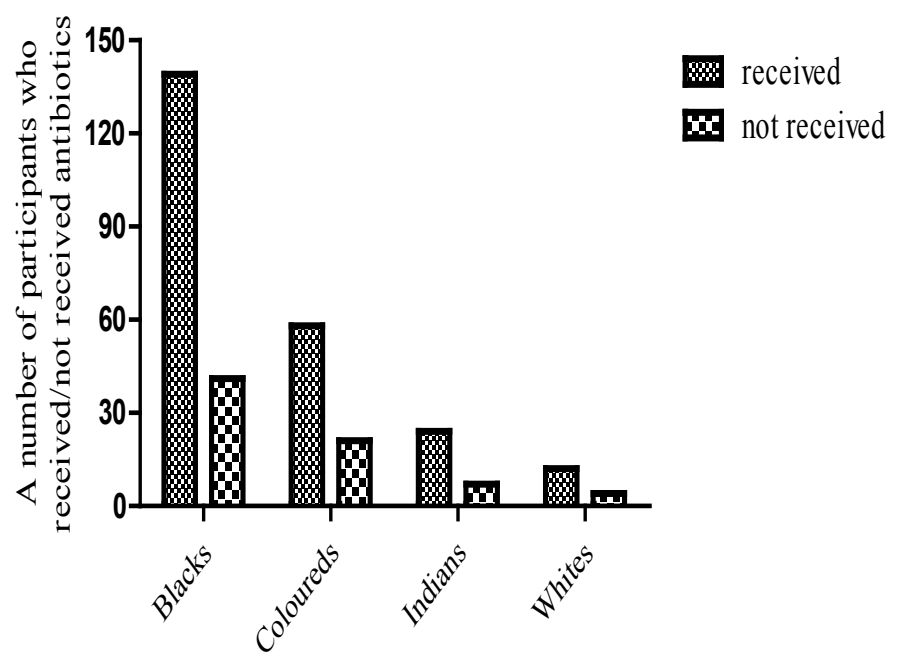

Figure 2: Prescribing of antibiotics as result of requests or no requests from parents/guardians by racial groups.

However, the differences by racial groups were not statistically significant $(p=0.9)$. Participants who lived in the rural areas were four (4) times likely to receive an- tibiotics, and the odds for those who lived in the suburban and township areas were 2.2 and 3.1, respectively (Figure 3). However, the odds ratios across all the areas of settlement were not statistically significant $(p=0.5)$.

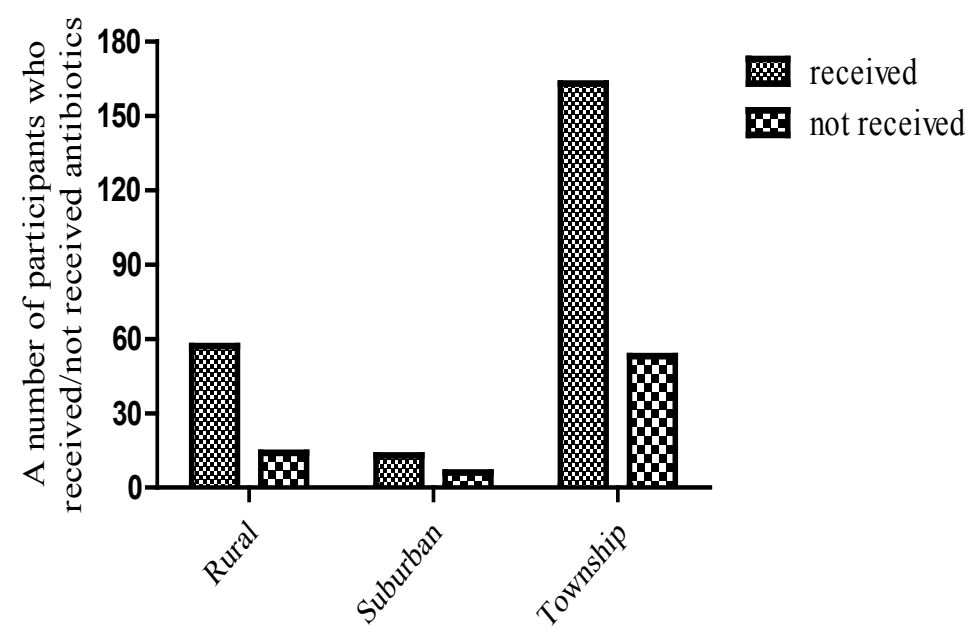

Figure 3: Prescribing of antibiotics as result of requests or no requests from parents/guardians by area of settlement. 
As shown in Figure 4, children accompanied by participants who passed matric, as their highest qualification, were three (3) times more likely (OR 3.1, 95\% CI 1.5 -
6.6, $\mathrm{p}<0.01$ ) and two times more likely (OR 1.9, 95\% CI $1.1-3.6, \mathrm{p}=0.03)$ to receive antibiotics for URTIs than those who were accompanied by participants who possessed a higher/college and primary/secondary qualifications, respectively.

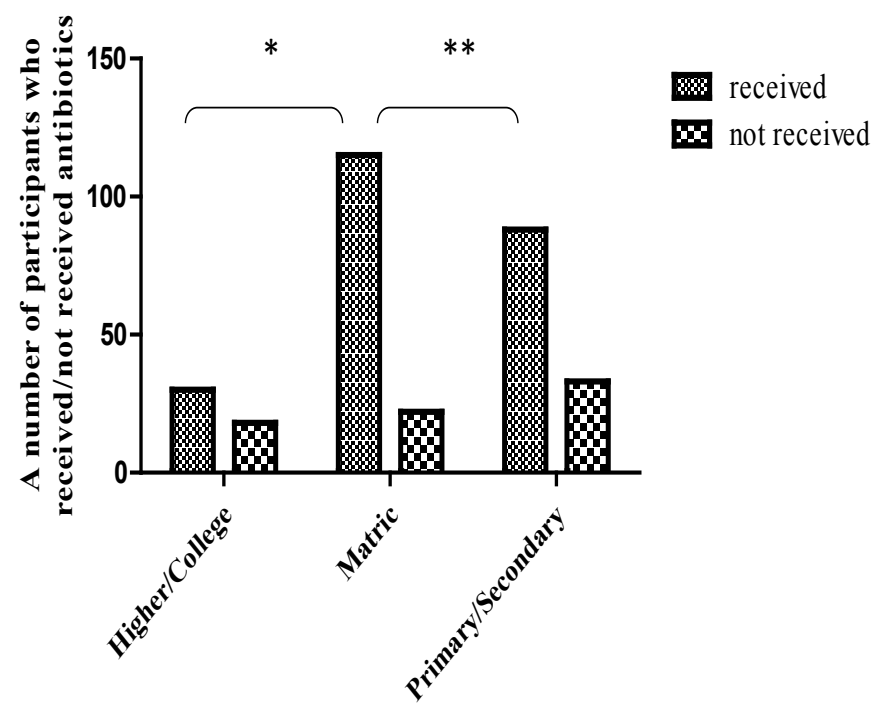

Figure 4: Prescribing of antibiotics as result of requests or no requests from parents/guardians by level of education.

$$
{ }^{*} \mathrm{p}<0.01,{ }^{* *} \mathrm{p}=0.03
$$

There was no statistically significant difference $(\mathrm{p}=0.07)$ between females and males for receiving antibiotics for URTIs (Figure 5).

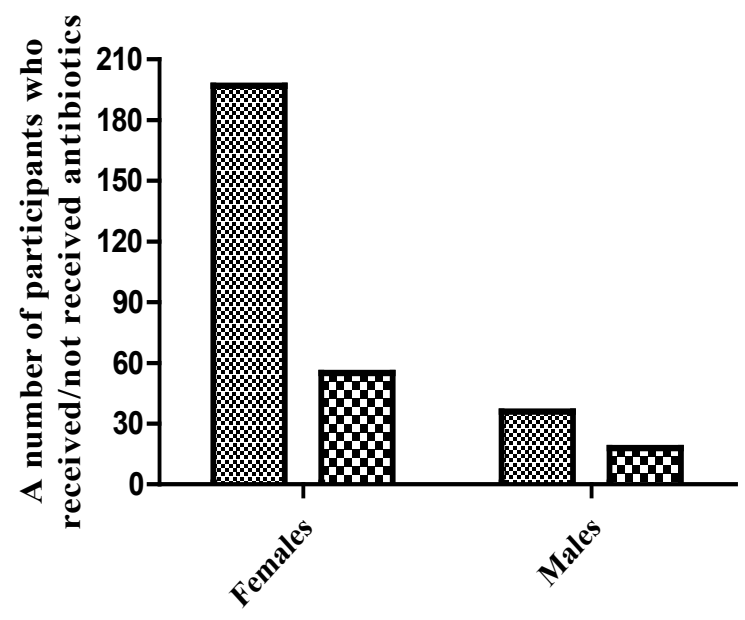

Figure 5: Prescribing of antibiotics as result of requests or no requests from parents/guardians by area of settlement. 
Knowledge about Administration/Storage of Antibiotics

Encouragingly, $100 \%$ of participants knew that antibiotics need to be administered with a medicine measure; and none mentioned that they would administer antibiotics by mixing medicine with baby feeds. Although Whites, as shown in Figure 6, were more likely (odds 2.2) to use syringes to administer antibiotics, there was no statistically significant $(\mathrm{p}=0.5)$ difference across the racial groups in terms of a preferred method of administration. It was worth to note that $33 \%(n=101)$ of participants did not know how long antibiotics need to be administered. However, there were no statistically significant differences in the knowledge on the length of administration of antibiotics in terms of areas of settlement $(p=0.2)$, race $(p=0.8)$, the level of education $(p=0.7)$ and all the age groups $(p=0.07)$. Interestingly, the participants aged $\leq 19$ years old were more likely (OR 2.2; 95\% CI, $1.2-3.1 ; \mathrm{p}=0.03$ ) to know how long antibiotics need to be administered than those aged 20-35 years old (Figure 7). The majority of participants mentioned that they will store antibiotics in the medicine cupboard, dry cool places and in the fridges. No participants mentioned that they would store them in the grocery cupboards.

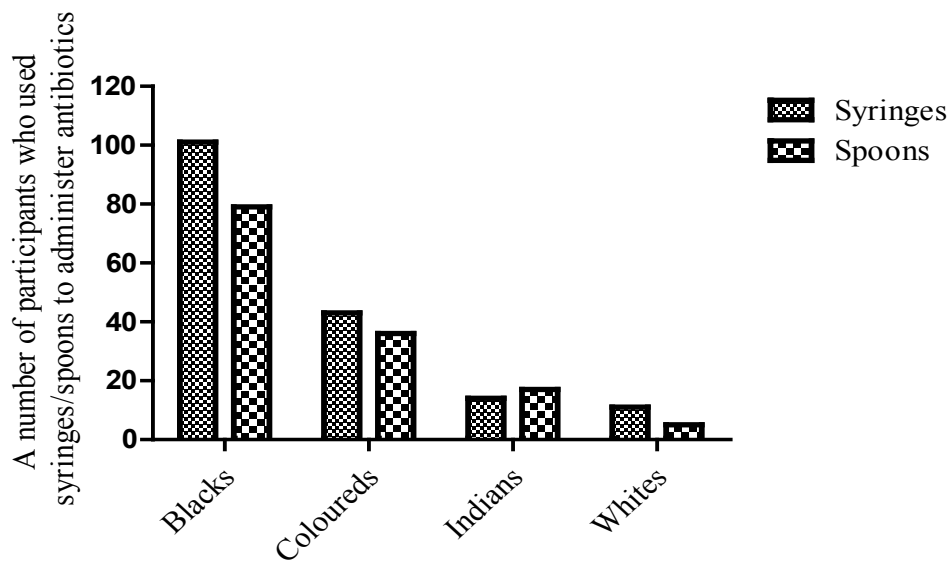

Figure 6: Methods preferred by various racial groups for administration of antibiotics.

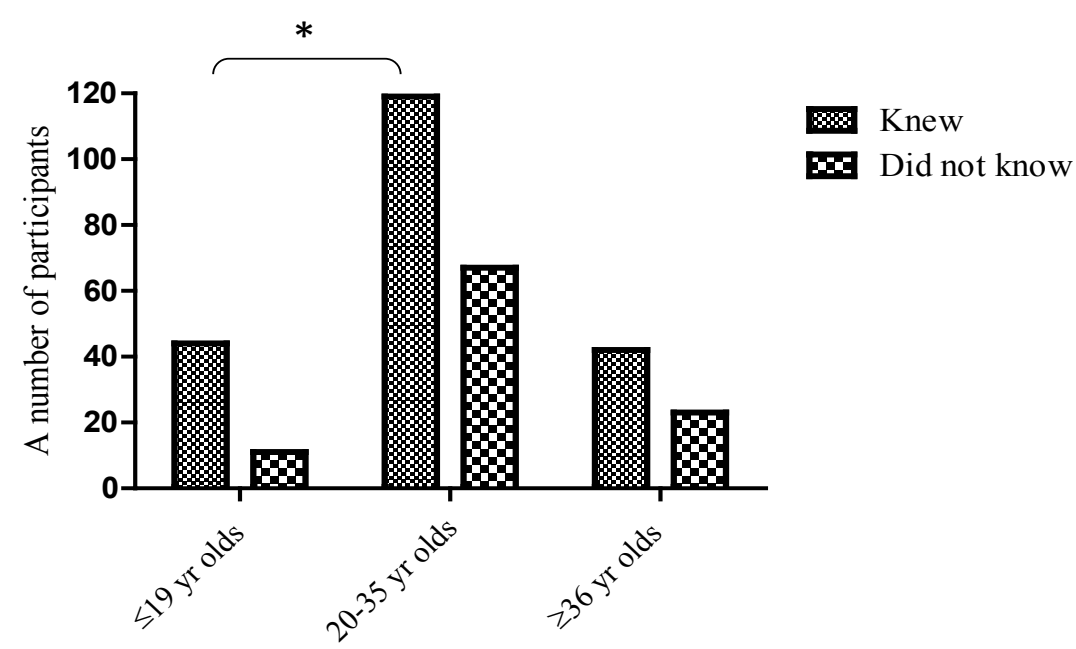

Figure 7: Knowledge of how long antibiotics should be administered. ${ }^{*} \mathrm{p}=0.03$. 


\section{Knowledge about Antibiotics Resistance}

More than half of the respondents, 53\% $(n=163)$, were aware or had heard about antibiotic resistance. However, $12 \%(\mathrm{n}=36)$ of participants said they had never heard of antibiotic resistance, and 35\% $(n=107)$ of the respondents said they were not sure if they have ever heard of antibiotic resistance. Forty three percent $(n=131)$ of participants thought antibiotic resistance was very dangerous. The vast majority $(74 \%, \mathrm{n}=225)$ of participants mentioned that antibiotics will be less effective in treating their illnesses in the future, when asked what they thought would happen if someone takes antibiotics when they did not need to. However, $53 \%(n=163)$ of respondents were not sure what impact of the misuse of antibiotics or the impact on the effectiveness of antibiotics for other people in the community if someone took antibiotics when there was no need.

\section{Discussion}

At the beginning of this study, the researchers hypothesised that the parents/guardians were at the centre of unnecessary prescribing of antibiotics for children with URTI. However, it was a cause for grave concern that the majority of participants in this study received antibiotics for URTIs, without even exerting any pressure on the prescriber(s). In support of the findings of this study, Zyoud and colleagues (2015) recently-reported that more than $38 \%$ of parents, who participated in their study, never asked the paediatrician(s) to prescribe antibiotics. ${ }^{23}$ This study showed that only $27 \%$ of participants requested antibiotics therapy. Also, it is on record that patients, in various settings, were extremely passive and rarely offered their opinion or initiated discussion about any aspect of the treatment. ${ }^{24}$ Therefore, the findings of this research suggest that it is in fact the majority of the prescribers, and not the parents/guardians (as it was anticipated), who are likely to exacerbate the challenge of multi-drug resistance due to irrational prescribing patterns. Lack or insufficient practice of evidence-based medicine and failure to adhere to the standard treatment guidelines among the various general practitioners have been reported in Ghana, ${ }^{25}$ Swe$\operatorname{den}^{26}$ and in many countries across the world. ${ }^{27}$

This study has also identified residential area, ethnicity, parents' age, gender and educational level as significant factors associated with parents' knowledge and attitudes concerning judicious antibiotic use in children. As it was with a similar research that was conducted in
Cyprus ${ }^{28}$ the majority of the respondents in this study were females. This could be due to parenting patterns among the population from which the sample of this study was drawn. It is also possible that female guardians/mothers are generally more concerned about their children's health, and are quicker to sought help, than are the children's fathers. With regards to parents' educational levels, it was noticed that most of the parents/ guardians had secondary and matric level of education, and a substantial amount had higher college education or a degree. In contrast, a study from Greece, ${ }^{29}$ showed that highest percentage of respondents had a low educational level. However, the findings of this study are in support of Adisa and colleagues (2018); they recently reported that, in Nigeria, the educational status of mothers/guardian influences the usage of antibiotic. ${ }^{30}$ Parents/guardians who participated in this study, especially those who lived in urban areas, had some knowledge about antibiotics. They mentioned that URTIs are viral. However, only one-third of participants acknowledged that they expected an antibiotic prescription from their physician for children with URTIs. This is because the participants, who expected antibiotics to be prescribed, believed that antibiotics would be helpful to decrease the duration of symptoms or complications of URTIs and accelerate recovery. A randomised trial of prescribing approaches for sore throat among 716 patients in primary care in Wessex in 1997, showed that those who received antibiotics were more likely to present with thillness and expected antimicrobial therapy in the near future. ${ }^{31}$

Encouragingly, in this study, the parents were very knowledgeable regarding administration and storage of antibiotics for children's URTIs; it is worth noticing that almost half of the participants did not know for how long they must administer antibiotics to children. Also, it was interesting that the older participants, in this study, had lesser demands for antimicrobial therapy than younger parents/guardians. Therefore parenting experience may have led to less anxiousness when the children were sick. However, more research is needed to explain this finding.

The study conducted in Saudi Arabia, recently reported that mainly parents with higher levels of education were associated with better knowledge and correct antibiotic practices for children with URTIs. ${ }^{32}$ However, in this study almost all participants with matric level of education received the antibiotics followed by the 
participants with higher level of education. Therefore, it seems, in South Africa, more educated parents are more like to request/receive antibiotic therapy. Also, readily available information, especially on the internet, may have contributed to the demand of antibiotics by the more educated participants as compared to those who had primary/secondary level of education only. However, more research is needed to explain this finding. Remarkably, the vast majority of parents/guardians (74\%) acknowledged that inappropriate and misuse reduces efficiency of antibiotics. Similarly, in a cross-sectional study conducted in Cyprus, ${ }^{28}$ it was reported that the majority of parents acknowledged that antibiotics have side effects (93\%), agreed that misuse reduces their efficiency and increases bacteria resistance $(90 \%)$. In this study, about half of participants (53\%) knew or were really aware about antibiotic resistance. About $12 \%$ have never heard of antibiotic resistance and $35 \%$ were not sure if they know about antibiotic resistance. Less than half of the participants (about $43 \%$ ) of participants thought antibiotic resistance was dangerous. However, the public understanding about antibiotic resistance was reported to be vastly disparate in other parts of the world too. ${ }^{33}$

\section{Limitations and future studies}

Although this study assessed the use of antibiotics in children with URTIs in the public healthcare settings, this problem extends to adults and the private healthcare settings as well. For example Alabadi and colleagues (2014) as well as Hassali and colleagues (2015), have recently-reported that there is a high prescribing and dispensing of antibiotics for URTIs among private general practitioners (GPs) and community pharmacists in Malaysia. ${ }^{34,35}$ Recently, Tiroyakgosi and colleagues (2018) reported that there was $73 \%$ antibiotic-prescribing among private ambulatory care patients with URTIs in Botswana. ${ }^{36}$

A follow-up study, i.e., the "Prescriber Education and Support Programme" (PESP), focusing mainly on the intervention aimed at (re)educating and supporting the prescribers both in public and private healthcare settings, has commenced in Durban and Pietermaritzburg, South Africa. Among others, the PESP utilises the WHO's "Guide to Good Pescribing" manual to teach the prescribers about rational prescribing process. ${ }^{6}$

\section{Conclusion}

Antimicrobial therapy has played a major role in the control and cure of many life-threatening respiratory diseases. The findings of this study has shown that the use of antibiotics for the treatment of URTIs in children is the elephant in the room. Effective introduction of guidelines and monitoring antimicrobial use increases the quality of prescribing -- and eventually lower AMR rates. ${ }^{37}$ Therefore, there is, indeed, a need for educational interventions for the doctors and nurses, both in public and private healthcare settings, who often prescribe rationally in one area but irrationally in another. ${ }^{38}$ Also, a significant reduction of AMR will require active participation of clinicians in audits and research for a long-lasting success of antimicrobial stewardship programmes in South Africa, in particular, and in the world. ${ }^{8,15}$

\section{Conflict of interest}

The authors declare that they have no conflict of interest.

\section{Funding source}

There was no funding for this work.

\section{References}

1. Cars O, Högberg LD, Murray M, Nordberg O, Sivaraman S, Lundborg CS, So AD, Tomson G. Meeting the challenge of antibiotic resistance. British Medical Journal 2008; 337: a1438. DOI: 10.1136/bmj.a1438.

2. Marston HD, Dixon DM, Knisely JM, Palmore TN, Fauci AS. Antimicrobial Resistance. Journal of American Medical Association 2016; 316(11): 1193-1204. doi: 10.1001/jama.2016.11764.

3. Pulcini C, Gyssens IC. How to educate prescribers in antimicrobial stewardship practices. Virulence 2013; 4(2): 192-202. doi: 10.4161/viru.23706.

4. WHO, World Health Organization (2001) Interventions and strategies to improve the use of antimicrobials in developing countries. Drug Management Program. http://www.who.int/csr/resources/publications/drugresist/WHO_CDS_CSR_DRS_2001_9/ en/. Accessed on 14 April 2019.

5. CDC, Interagency Task Force on Antimicrobial Resistance. 2012 (updated). A Public Health Action Plan to Combat Antimicrobial Resistance. Available from https://www.cdc.gov/drugresistance/pdf/action-plan-2012.pdf. Accessed on 22 April 2019.

6. WHO, World Health Organisation Guide to Good Prescribing, 1998. Available from http://apps. who.int/medicinedocs/pdf/whozip23e/whozip23e. pdf. Accessed on 14 April 2019. 
7. Roope LSJ, Smith RD, Pouwels KB. Buchanan J., Abel L, Eibich P, Butler CC, Tan PS, Walker AS, Robotham JV, Wordsworth S. The challenge of antimicrobial resistance: What economics can contribute. Science 2019; 364; eaau4679; 1-8.

8. Llor C, Bjerrum L. Antimicrobial resistance: risk associated with antibiotic overuse and initiatives to reduce the problem. Therapeutic Advances in Drug Safety 2014; 5(6): $229-241$

9. RAR, 2016. The Review on Antimicrobial Resistance final report of the Commission chaired by Jim O’Neill, downloaded from https://amr-review.org/ sites/default/files/160525_Final\%20paper_with\%20 cover.pdf. Accessed on 22 May 2019.

10. Zillich AJ, Sutherland JM, Wilson SJ, et al. Antimicrobial use control measures to prevent and control antimicrobial resistance in US hospitals. Infection Control and Hospital Epidemiology 2006; 27(10): 1088 - 95.

11. Krishnan A, Amarchand R, Gupta V, Lafond KE, Suliankatchi RA, Saha S, Rai S, Misra P, Purakayastha DR, Wahi A, Sreenivas V, Kapil A, Dawood F, Pandav CS, Broor S, Kapoor SK, Lal R, Widdowson MA. Epidemiology of acute respiratory infections in children - preliminary results of a cohort in a rural north Indian community. BMC Infectious Diseases 2015; 15: 462. doi: 10.1186/s12879-015-1188-1.

12. Liu J, Ai H, Xiong Y, Li F, Wen Z, Liu W, Li T, Qin K, Wu J, Liu Y. Prevalence and correlation of infectious agents in hospitalized children with acute respiratory tract infections in Central China. PLoS One 2015; 10(3): e0119170. doi: 10.1371/journal.pone.0119170.

13. Nair H, Brooks WA, Katz M, Roca A, Berkley JA, Madhi SA, Simmerman JM, Gordon A, Sato M, Howie S, Krishnan A, Ope M, Lindblade KA, Carosone-Link P, Lucero M, Ochieng W, Kamimoto L, Dueger E, Bhat N, Vong S, Theodoratou E, Chittaganpitch M, Chimah O, Balmaseda A, Buchy P, Harris E, Evans V, Katayose M, Gaur B, O'Callaghan-Gordo C, Goswami D, Arvelo W, Venter M, Briese T, Tokarz R, Widdowson MA, Mounts AW, Breiman RF, Feikin DR, Klugman KP, Olsen SJ, Gessner BD, Wright PF, Rudan I, Broor S, Simões EA, Campbell H. Global burden of respiratory infections due to seasonal influenza in young children: a systematic review and meta-analysis. Lancet 2011; 378(9807): 1917-30. doi: 10.1016/S01406736(11)61051-9.

14. Van Boeckel TP, Gandra S, Ashok A, Caudron Q, Grenfell BT, Levin SA, Laxminarayan R. Global antibiotic consumption 2000 to 2010: An analysis of national pharmaceutical sales data. Lancet Infectious Diseases 2014; 14(8): 742 - 750 .
15. Essack SY, Desta AT, Abotsi RE, \& Agoba EE. Antimicrobial resistance in the WHO African region: current status and roadmap for action. Journal of Public Health (Oxford, England) 2017; 39(1): 8 - 13.

16. Poole MD. Appropriate antibiotic use in treating respiratory tract infections. American Journal of Managed Care 2001; 7(6 Suppl): S178 - S182.

17. Volturo GA, Low DE, Aghababian R. Managing acute lower respiratory tract infections in an era of antibacterial resistance. American Journal of Emergency Medicine; 2006; 24(3): 329-42.

18. Nyquist AC, Gonzales R, Steiner JF, Sande MA. Antibiotic prescribing for children with colds, upper respiratory tract infections, and bronchitis. Journal of American Medical Association 1998; 279(11): 875 877. Erratum in: Journal of American Medical Association 1998; 3; 279(21):1702.

19. RSA STG Republic of South Africa. Essential Drugs Programme. Primary Healthcare Standard Treatment Guidelines and Essential Medicines List. 5th ed. Republic of South Africa: National Department of Health; 2014.

20. Neiderman, M. S., Skerrett, S. J., Yamauchi, T. (1998). Antibiotics or not? Managing patients with respiratory infections. Patient Care 1998; 32(1): 60 - 89.

21. Ebell $\mathrm{MH}$, Radke T. Antibiotic use for viral acute respiratory tract infections remains common. American Journal of Managed Care. 2015; 21(10): e567 e575.

22. Cullinan K. 2006. Health services in South Africa: A basic introduction, downloaded from https:// www.health-e.org.za/wp-content/uploads/2013/04/ Health_services_briefing_doc.pdf. Accessed on 23 April 2019.

23. Zyoud SH, Abu Taha A, Araj KF, Abahri IA, Sawalha AF, Sweileh WM, Awang R, Al-Jabi SW. Parental knowledge, attitudes and practices regarding antibiotic use for acute upper respiratory tract infections in children: a cross-sectional study in Palestine. BMC Paediatrics 2015; 15: 176.

24. Makoul G, Arntson P, Schofield T. Health promotion in primary care: physician-patient communication and decision making about prescription medications. Social Science Medicine. 1995; 41(9): 1241 - 1254. PubMed PMID: 8545677.

25. Prah J, Kizzie-Hayford J, Walker E, Ampofo-Asiama A. Antibiotic prescription pattern in a Ghanaian primary health care facility. Pan African Medical Journal 2017; 28: e214.

26. Neumark T, Brudin L, Mölstad S. Antibiotic prescribing in primary care by international medical 
graduates and graduates from Swedish medical schools. Family Practice 2015; 32 (3): 343 - 347.

27. Md Rezal RS, Hassali MA, Alrasheedy AA, Saleem F, Md Yusof FA, Godman B. Physicians' knowledge, perceptions and behaviour towards antibiotic prescribing: a systematic review of the literature. Expert Reviews of Anti-Infective Therapy 2015; 13 (5): 665 - 680.

28. Rousounides A., Papaevangelou V., Hadjipanayis A., Panagakou S., Theodoridou M., Syearsogiannopoulos G. and Hadjichristodoulou G. Descriptive Study on Parents' Knowledge, Attitudes and Practices on Antibiotic Use and Misuse in Children with Upper Respiratory Tract Infections in Cyprus. International Journal of Environmental Research and Public Health 2011; 8 (8); $3246-3262$.

29. Ferech M, Coenen S, Malhotra-Kumar S, Dvorakova K, Hendrickx E, Suetens C, Goossens H; ESAC Project Group. European Surveillance of Antimicrobial Consumption (ESAC): outpatient antibiotic use in Europe. Journal of Antimicrobial Chemotherapy 2006; 58(2): $401-407$.

30. Adisa R, Orherhe OM, Fakeye TO. Evaluation of antibiotic prescriptions and use in under-five children in Ibadan, South Western Nigeria. African Health Sciences 2018; 18 (4): 1189 - 1201.

31. Little P, Williamson I, Warner G, Gould C, Gantley M, Kinmonth AL. Open randomised trial of prescribing strategies in managing sore throat. British Medical Journal 1997; 314(7082): 722 - 727.

32. Alrafiaaha A.S., Alqarnya M.H., Alkubedana H.Y., AlQueflieb S., Omairca A. Are the Saudi parents aware of antibiotic role in upper respiratory tract infections in children? College Journal of Infection and Public Health 2017; 10 (1): 579 - 585.

33. Pinder R, Sallis A, Berry D, Chadborn T. Be- haviour change and antibiotic prescribing in healthcare settings, literature review and behavioural analysis. $D e-$ partment of Health, Public Health England 2015. https:/ / spiral.imperial.ac.uk/bitstream/10044/1/22194/2/ Behaviour_Change_for_Antibiotic_Prescribing_-_FINAL.pdf. Accessed on 25 March 2019.

34. Alabid AH, Ibrahim MI, Hassali MA. Antibiotics Dispensing for URTIs by Community Pharmacists (CPs) and General Medical Practitioners in Penang, Malaysia: A Comparative Study using Simulated Patients (SPs). Journal of Clinical and Diagnostic Research 2014; 8(1): $119-123$.

35. Hassali MA, Kamil TKT, Md Yusof FA, Alrasheedy AA, Yusoff ZM, Saleem F, AL-Tamimi SK, Wong ZY, Aljadhey H, Godman B. General practitioners' knowledge, attitude and prescribing of antibiotics for upper respiratory tract infectionin Selangor, Malaysia: findings and implications. Expert Review of Anti-infective Therapy 2015; 13(4); $511-520$.

36. Tiroyakgosi C, Matome M, Summers E, Mashalla Y, Paramadhas BA, Souda S, Malone B, Sinkala F, Kgatlwane J, Godman B, Mmopi K, Massele A. Ongoing initiatives to improve the use of antibiotics in Botswana: University of Botswana symposium meeting report. Expert Review of Anti-Infective Therapy 2018; 16(5): $381-384$.

37. Matsitse TB, Helberg E, Meyer JC, Godman B, Massele A, Schellack N. Compliance with the primary health care treatment guidelines and the essential medicines list in the management of sexually transmitted infections in correctional centres in South Africa: findings and implications. Expert Review of Anti-infective Therapy 2017; 15(10): 963 - 972.

38. Lilja J, Larsson S. Social pharmacology: unresolved critical issues. International Journal of Addictions 1994; 29 (13): 1647-1737. 